\title{
Research review: reading comprehension in developmental disorders of language and communication
}

Article

Accepted Version

Ricketts, J. (2011) Research review: reading comprehension in developmental disorders of language and communication. Journal of Child Psychology and Psychiatry, 52 (11). pp. 11111123. ISSN 0021-9630 doi: https://doi.org/10.1111/j.14697610.2011.02438.x Available at

https://centaur.reading.ac.uk/27893/

It is advisable to refer to the publisher's version if you intend to cite from the work. See Guidance on citing.

To link to this article DOI: http://dx.doi.org/10.1111/j.1469-7610.2011.02438.x

Publisher: Wiley

All outputs in CentAUR are protected by Intellectual Property Rights law, including copyright law. Copyright and IPR is retained by the creators or other copyright holders. Terms and conditions for use of this material are defined in the End User Agreement.

www.reading.ac.uk/centaur 
Central Archive at the University of Reading

Reading's research outputs online 
Running head: READING COMPREHENSION IN DEVELOPMENTAL DISORDERS OF LANGUAGE AND COMMUNICATION: A REVIEW

Reading Comprehension in Developmental Disorders of Language and Communication: A Review

Second revision: 29 April 2011

Jessie Ricketts

Centre for Educational Development, Appraisal and Research (CEDAR), University of Warwick

Address for correspondence:

Jessie Ricketts

Centre for Educational Development, Appraisal and Research (CEDAR)

University of Warwick

Coventry CV4 7AL

jessie.ricketts@warwick.ac.uk

Tel: +44(0)7824541 189 
Ricketts/ 2

\begin{abstract}
In this review, the Simple View of Reading is used as a framework for considering reading comprehension in children and adolescents with specific language impairment (SLI), Down syndrome (DS) and autism spectrum disorders (ASD). Deficits in reading comprehension have been reported in each group and reading comprehension is typically more impaired than word recognition. However, there is also evidence that some children and adolescents with DS, ASD and a history of SLI develop age appropriate or above reading comprehension and word recognition skills. This review of the literature indicates that factors including word recognition, oral language, nonverbal ability and working memory may explain reading comprehension difficulties in SLI, DS and ASD. In addition, it highlights methodological issues, implications of poor reading comprehension and fruitful areas for future research.
\end{abstract}


Reading Comprehension in Developmental Disorders of Language and Communication: A Review

Early in reading development children must learn to map letters onto sounds so that they can decode and recognise words. However, the ultimate goal of reading is to understand the messages conveyed by text, and simply being able to read words and texts accurately is not sufficient for reading comprehension to occur. Reading comprehension is a complex skill dependent on a number of cognitive processes. For example, to understand written text, words need to be recognised and their meanings accessed, relevant background knowledge also needs to be activated, and inferences generated as information is integrated during the course of reading. In addition, control processes monitor both ongoing comprehension and the internal consistency of text, allowing the reader to initiate repair strategies (e.g., rereading) if comprehension breakdown is detected.

The majority of reading research has focused on word recognition skills, but there is now also a substantial literature on reading comprehension development, as described in a number of recent reviews (for example, see Cain \& Oakhill, 2007; Hulme \& Snowling, 2009; Nation, 2005). A growing number of studies have also been concerned with the reading comprehension difficulties that can be observed in children with a range of developmental disorders. Of particular note are three groups of children for whom there is sufficient existing research to warrant review, those with specific language impairment (SLI), Down syndrome (DS) and autism spectrum disorders (ASD; see Mervis, 2009 for details of the few studies exploring reading comprehension in Williams syndrome). Although reading research with these groups has been summarised elsewhere (Bishop \& Snowling, 2004; Grigorenko, Klin, \& Volkmar, 2003; Kay-Raining Bird \& Chapman, in press; Nation, 1999; Nation \& Norbury, 2005), none of these reviews have focused on reading comprehension whilst also considering 
the three groups together. This review uses the Simple View of Reading as a framework from which to examine existing reading comprehension research on children with SLI, DS and ASD.

\section{The Simple View of Reading}

To become a skilled reader, a child needs to master two sets of skills; word recognition and oral language comprehension processes. Both sets of skills are necessary to access the meaning conveyed by text, and neither is sufficient on its own. However, the relative contribution of these skills changes with age and reading development (Chen \& Vellutino, 1997; Gough et al., 1996). For beginners, word recognition presents the greatest barrier to reading success but as word recognition improves, the ability to read and understand texts is increasingly determined by oral language skill. The notion that both word recognition and oral language comprehension contribute to reading is embodied by the Simple View of Reading (Gough \& Tunmer, 1986). Figure 1 depicts the two components of this model as two continuous and separable dimensions, with word recognition processes ranging from poor to good on the horizontal axis and language comprehension skills ranging from poor to good on the vertical axis (see also Bishop \& Snowling, 2004; Catts, Adlof, \& Weismer, 2006; Nation \& Norbury, 2005).

\section{INSERT FIGURE 1 ABOUT HERE}

At the extremes, Figure 1 highlights four possible reading profiles at A, B, C and D. For many children, word recognition and language comprehension skills develop in parallel, resulting in children who vary from having poor word recognition and language comprehension skills for their age to children who exhibit skilled performance across both domains (quadrants C and B in Figure 1 respectively). Indeed, substantial correlations between the two components are frequently reported (e.g., Chen \& Vellutino, 1997; Cutting \& Scarborough, 2006; Gough, Hoover, \& Peterson, 1996; Nation \& Snowling, 1997). 
However, the Simple View considers word recognition and oral language comprehension to be relatively independent. This is supported by the dissociations between components that are observed in children with reading disorders. Dyslexia (A in Figure 1) is characterised by poor word recognition that typically occurs alongside unimpaired comprehension skills (e.g., Catts et al., 2006; Frith \& Snowling, 1983; Nation \& Snowling, 1998). The opposite profile of reading and language comprehension difficulties despite age-appropriate reading accuracy (D in Figure 1) is observed in poor comprehenders (for reviews, see Cain \& Oakhill, 2007; Hulme \& Snowling, 2009; Nation, 2005). Poor comprehenders may have attracted less attention than children with dyslexia but appear to be more prevalent with estimates of around 7-10\% (Clarke, Snowling, Truelove, \& Hulme, 2010; Nation, Cocksey, Taylor, \& Bishop, 2010) compared with 3-6\% for dyslexia (Hulme \& Snowling, 2009).

Further evidence that word recognition and oral language comprehension are relatively independent comes from factor analytic approaches (e.g., Savage, 2006), behavioural genetic studies and longitudinal research showing that the two components are dependent on different linguistic and cognitive abilities. Behavioural genetic analyses of reading comprehension have demonstrated significant genetic and (shared) environmental influences, with genetic factors explaining a higher proportion of variance than the environment (Byrne et al., 2009; Harlaar et al., 2010; Keenan et al., 2006). Importantly though, word recognition and oral language comprehension accounted for independent genetic influences on reading comprehension. In longitudinal studies, progress in word recognition is predicted by children's phonological skills, amongst other things, whereas progress in comprehension is more related to factors such as vocabulary and grammatical understanding (Catts et al., 2006; Muter, Hulme, Snowling, \& Stevenson, 2004; Oakhill, Cain, \& Bryant, 2003). Consistent with this, phonological deficits are implicated in developmental dyslexia (for reviews, see Snowling, 2000; Vellutino, Fletcher, Snowling, \& Scanlon, 2004) whereas poor 
comprehenders show unimpaired performance in phonological tasks (Catts et al., 2006; Stothard \& Hulme, 1995) alongside impairments across a range of nonphonological language tasks (Catts et al., 2006; Nation, Clarke, Marshall, \& Durand, 2004). Particularly convincing evidence that oral language plays a causal role in reading difficulty comes from prospective longitudinal studies (Carroll \& Snowling, 2004; Nation et al., 2010) and randomised controlled trials (e.g., Clarke et al., 2010; Hatcher et al., 2006).

Since oral language difficulties are central to SLI and are common in DS and ASD, it follows that these children will experience difficulties with reading. The language and literacy skills of children with SLI, DS and ASD will be reviewed to establish the reading profiles that have been reported and whether reading success is determined by word recognition and/or oral language difficulties as assumed by the Simple View of Reading. Further, this review aims to highlight gaps in the literature and extend the Simple View by identifying variables beyond word recognition and oral language that explain individual differences in reading comprehension.

\section{Specific language impairment (SLI)}

Much of the research investigating reading comprehension in children with impaired language has focused on children with SLI. SLI is diagnosed in the presence of impaired oral language despite no evidence of physical impairment or deficits in other areas of cognition (including nonverbal IQ). The language profiles of children with SLI are heterogeneous and prevalence estimates vary depending on the specific criteria used, but are typically between 3\% and 10\% (Hulme \& Snowling, 2009).

There is ample evidence that children with SLI exhibit reading difficulties. For example, Bishop and colleagues conducted a prospective longitudinal study of children who had received a diagnosis of SLI prior to formal schooling (Bishop \& Adams, 1990; Bishop \& Edmundson, 1987; Snowling, Bishop, \& Stothard, 2000; Stothard, Snowling, Bishop, 
Chipchase, \& Kaplan, 1998). At 8 and 15 years of age, the SLI group showed impaired performance on both reading accuracy and comprehension tasks relative to chronological age-matched controls. In addition, there was a tendency for children to experience greater difficulty with reading comprehension than word recognition (see also Bishop, McDonald, Bird, \& Hayiou-Thomas, 2009; Botting, Simkin, \& Conti-Ramsden, 2006; Catts, Fey, Tomblin, \& Zhang, 2002).

At a group level reading scores are generally depressed in children with a history of impaired language. However, scores are highly variable and profiles can fall into all of the four quadrants depicted in Figure 1 (Catts et al., 2002; Palikara, Dockrell, \& Lindsay, in press). Catts et al. (2002) conducted a longitudinal investigation of component reading skills in children with a preschool diagnosis of SLI. Although most studies of reading in SLI are limited by small and potentially unrepresentative samples, in this case a large group of children $(\mathrm{N}=117)$ were drawn from an epidemiological study. Catts et al. observed unimpaired reading in approximately $40 \%$ of their sample at age 8 and 10 years. Although this finding is somewhat surprising, language impairments had resolved for many children and resolved language difficulties were associated with better reading outcome (see also Bishop \& Adams, 1990; Stothard et al., 1998). It is also worth noting that this could reflect ‘illusory recovery' (Scarborough \& Dobrich, 1990) and these children might go on to experience subtle reading difficulties in adolescence and adulthood (cf. Stothard et al., 1998).

The majority of children in Catts et al.'s (2002) study showed reading impairments. Approximately 35\% of their sample showed deficits in both word recognition and reading comprehension, $15 \%$ showed a 'poor comprehender' profile of age-appropriate word recognition alongside impaired reading comprehension and $10 \%$ showed the opposite 'dyslexia' profile. Observed behavioural similarities between SLI and dyslexia have led to some recent debate about whether they are distinct disorders or represent opposite ends of a 
continuum (e.g., Bishop \& Snowling, 2004; Botting et al., 2006; Catts, Adlof, Hogan, \& Weismer, 2005). There is some consensus that SLI and dyslexia are distinct. This is partly evidenced by the observation that while reading and language difficulties in dyslexia are usually restricted to word recognition and phonological processing, in SLI broader language and reading impairments are also often reported, akin to those observed in poor comprehenders (see Catts et al., 2006; Nation et al., 2004).

In their review, Bishop and Snowling (2004) used the Simple View of Reading to consider heterogeneity in the reading and language profiles of children with SLI (see also Nation \& Norbury, 2005). They concluded that a child's reading profile would be determined by strengths and weaknesses across phonological and nonphonological (e.g., semantics, grammar) language domains, with phonological impairments constraining word recognition and nonphonological impairments limiting comprehension. As well as determining the nature of a child's reading deficits, a child's language profile may determine when their difficulties will be most apparent. Snowling et al. (2000) suggested that phonological impairments will place children at risk for reading difficulties early in development, when individual differences in reading are driven primarily by word recognition, whereas more general language impairments will compromise reading later on, when fluency and reading comprehension are more important.

Research on SLI is consistent with the Simple View of Reading because it suggests that both word recognition and language comprehension are barriers to reading success in this group. Indeed, Botting et al. (2006) showed that both word recognition and oral language at age 7 years uniquely predicted reading comprehension four years later. However, nonverbal ability may also be an important factor in predicting levels of reading comprehension attainment (see also Botting et al., 2006; Catts, Bridges, Little, \& Tomblin, 2008; Catts et al., 2002; Snowling et al., 2000). In Catts et al.'s (2002) large scale longitudinal study, children 
with language impairments accompanied by nonverbal cognitive deficits showed poorer reading comprehension scores than children with SLI, even after controlling for initial differences in language. Relatedly, children selected to have reading comprehension difficulties often exhibit poor nonverbal IQ (Nation, Clarke, \& Snowling, 2002). Further, Catts et al. (2002) found that nonverbal ability at 6 years was a significant predictor of reading comprehension at 8 years after controlling for a measure of oral language (grammar). The exact mechanisms that drive the relationship between nonverbal ability and reading comprehension are unclear, but Catts et al. tentatively suggested that the link might be underpinned by visual-spatial and analytic skills or somehow mediated by higher order verbal skills (e.g., verbal reasoning). In summary, although language impairments before the onset of reading instruction are a risk factor for reading difficulties, not all children with a history of SLI exhibit reading difficulties later in development. Further, it is important to take nonverbal ability into account when considering the impact of impaired language on reading comprehension.

\section{Down Syndrome (DS)}

The incidence of DS is estimated at approximately 13 out of 10,000 live births (Besser, Shin, Kucik, \& Correa, 2007). DS is associated with moderate to severe learning difficulties alongside speech and language impairments. Typically, language is well below age expectations, with expressive language more impaired than receptive language and syntactic skills weaker than lexical skills (e.g., Chapman, 1997). There are relatively few published studies on reading in DS and still fewer that have measured reading comprehension as well as accuracy. However, the data that are available suggest that reading acquisition is slow but that the majority of individuals with DS achieve measurable levels of reading by adulthood (for a review, see Kay-Raining Bird \& Chapman, in press). 
Byrne et al. (2002) investigated reading comprehension, word recognition and receptive language in 24 children and adolescents with DS at three time points over two years. At a group level, reading comprehension and word recognition were low relative to chronological age but substantially higher than receptive language. Further, there was some discrepancy between component reading scores, with low reading comprehension relative to word recognition. While improvement in word recognition was observed over time, raw reading comprehension scores showed little change. These findings are consistent with other studies of reading in DS, and with the proposal that the discrepancy between word recognition and reading comprehension increases with age (Boudreau, 2002; Cardoso-Martins, Peterson, Olson, \& Pennington, 2009; Kay-Raining Bird \& Chapman, in press; Laws \& Gunn, 2002; Roch, Florit, \& Levorato, in press; Roch \& Levorato, 2009). This profile of stronger word recognition relative to weaker reading comprehension has led researchers to compare children with DS to poor comprehenders (Groen, Laws, Nation, \& Bishop, 2006; Roch et al., in press). However, there are key differences between the groups. Word recognition is by definition at least age-appropriate in poor comprehenders. In addition, while DS is typified by substantially impaired IQ, the poor comprehender profile is not (Nation, et al., 2002).

Although Byrne et al. (2002) explored reading in some detail and also longitudinally, they did not explore relationships between reading comprehension and oral language. Reading comprehension and oral language have consistently been shown to correlate in DS (Boudreau, 2002; Laws \& Gunn, 2002; Roch et al., in press; Roch \& Levorato, 2009). For example, Roch and Levorato (2009) reported a significant correlation between reading comprehension and a measure of oral language comprehension. In this study, word recognition was measured alongside reading comprehension and language comprehension in adolescents with DS (aged 11-18 years) and younger typically developing controls (aged 6-7 years) matched for reading comprehension level. Consistent with previous research on 
reading in typically developing children (e.g., Keenan, Betjemann, \& Olson, 2008; Muter et al., 2004; Nation \& Snowling, 1997), both word recognition and language comprehension correlated with reading comprehension in the control group. However, for the adolescents with DS only oral language was associated with reading comprehension.

At first glance, the failure to observe a correlation between word recognition and reading comprehension suggests that the Simple View of Reading may not apply to individuals with DS. However, in typically developing individuals, the relationship between word recognition and reading comprehension decreases with increasing age and word recognition ability (e.g., Chen \& Vellutino, 1997; Gough et al., 1996) and is weaker in groups of children that show a dissociation between word recognition and reading comprehension (for example see correlations reported by Nation, Clarke, Wright, \& Williams, 2006). Thus, the lack of association could be explained by the greater age and word recognition skills of the DS group, relative to the controls. It is also worth noting that the adolescents in Roch and Levorato's (2009) study were speakers of Italian, a relatively transparent language where word reading accuracy reaches ceiling fairly quickly. Studies in English (a less transparent language) report significant correlations between word recognition and reading comprehension in DS (Byrne, MacDonald, \& Buckley, 2002; Cardoso-Martins et al., 2009).

Roch and colleagues (in press) have presented longitudinal data indicating that language comprehension predicts reading comprehension one year later, after controlling for earlier reading comprehension and word recognition. On the basis of their regression analyses, they argue that oral language is causally related to reading comprehension. However, it is worth noting that between the two testing points, language comprehension and reading comprehension scores changed very little. Further, the regression analyses on which they base their causal argument should be interpreted with caution as they were conducted with 
data from 10 participants, far fewer than is recommended for models with three predictor variables (Field, 2005).

Laws and Gunn (2002) conducted a longitudinal study with 30 children and adolescents with DS. At the outset of the study (time 1) individuals were aged 5-17 years and reading was re-assessed five years later at time 2. Instead of presenting correlations and regressions, Laws and Gunn compared the earlier nonverbal and verbal abilities of individuals who did or did not go on to become readers at time 2. Nonverbal ability, receptive language and language production at time 1 distinguished between readers and non-readers at time 2 but hearing level accounted for group differences on some language measures (receptive vocabulary and sentence repetition). This highlights an important issue: most studies of reading comprehension have failed to adequately control for hearing level and many individuals with DS experience hearing loss that may impact on reading and mediate the relationship between language and reading.

In summary, there is some consensus that although reading capacities vary widely in DS, this domain can be an area of relative strength compared to impoverished verbal and nonverbal abilities (Laws \& Gunn, 2002). Indeed, some cases of exceptional reading have been reported (e.g., Groen et al., 2006). However, when component reading skills are considered in some detail it appears that word recognition is typically well below average for age and reading comprehension and nonword reading scores are even lower (e.g., Byrne et al., 2002; Roch \& Jarrold, 2008). It is worth noting that studies of reading in DS tend to include groups of children and adolescents that vary widely in age and the extent to which samples are representative of DS as a whole is unclear. Also, DS groups are usually compared to much younger typically developing children who will likely have had less exposure to reading materials. 
ASD refers to a group of neurodevelopmental disorders characterised by impairments in social interaction and communication, and repetitive and restricted behaviours and interests. As with SLI, prevalence estimates vary according to the diagnostic criteria employed but a recent population study indicates that approximately $1 \%$ of children meet criteria for ASD (Baird et al., 2006). The main focus of research on reading in ASD has been to explore a 'hyperlexic' reading profile of precocious word recognition alongside poor comprehension (for reviews and recent findings, see Grigorenko et al., 2003; Nation, 1999; Newman et al., 2007; Saldaña, Carreiras, \& Frith, 2009). There is little consensus about the precise criteria for hyperlexia and not all children labelled hyperlexic have a diagnosis of ASD. Conversely, not all children with ASD could be considered hyperlexic - advanced word recognition skills are not typical of reading in ASD (e.g., Nation et al., 2006). As the literature on hyperlexia focuses on word recognition and has been extensively reviewed elsewhere (Grigorenko et al., 2003; Nation, 1999), the following review will focus on the small number of studies that have included more varied and representative ASD samples and have probed reading comprehension as well as word recognition.

Jones et al. (2009) administered standardised literacy measures to a group of 100 adolescents with ASD aged 14-16 years. The group showed a discrepancy between reading comprehension and word recognition (cf. SLI and DS); with a mean comprehension score that was well below the average range alongside a higher word recognition score. This group level discrepancy is consistent with other studies of component reading skills in ASD (Frith \& Snowling, 1983; Lindgren, Folstein, Tomblin, \& Tager-Flusberg, 2009; Nation et al., 2006; Newman et al., 2007). However, the magnitude of the discrepancy varies widely across studies, from one or two standard points (Lindgren et al., 2009) to one standard deviation or more (Nation et al., 2006; Newman et al., 2007). The average level of performance and 
degree of dissociation likely depends on the characteristics of the group of individuals studied.

The observation that reading comprehension is an area of particular weakness relative to more advanced word recognition echoes the reading profile observed in hyperlexia and the uneven profiles across cognitive domains that have frequently been reported in this group (e.g., Happé, 1999; Jones et al., 2009). This raises the question of whether poor reading comprehension accompanied by stronger word recognition is universally observed in ASD. Nation et al. (2006) provided a detailed description of reading performance in 41 children with ASD aged 6-16 years. Across reading tasks, scores ranged from floor to near ceiling levels (cf. Jones et al., 2009) and nine children did not have measurable reading skills. Of the 32 readers, all but one obtained a reading comprehension score that was below their ability to read texts accurately, with approximately $34 \%$ showing a discrepancy of more than one standard deviation. Nation and colleagues compare this to a substantially lower rate of $11 \%$ in a normative sample of 562 children. Notwithstanding, for the majority of the ASD sample, the two scores were within one standard deviation of each other. Further, reading comprehension and word recognition were significantly and positively correlated across the ASD group, although this correlation was substantially lower than that reported for the normative sample ( $r=.48$ versus .75 ). Thus, while a hyperlexic-like dissociation is prevalent in ASD, its magnitude can be small and reading comprehension and word recognition are correlated. Another striking finding from Nation et al.'s (2006) study is that while most children exhibited difficulties with reading accuracy, comprehension or both, some showed average or above reading in both domains. Nearly half of the sample (20 children) obtained age-appropriate or above word recognition scores and this subgroup comprised 10 'poor comprehenders' with reading comprehension scores below the average range and 10 'skilled comprehenders' with comprehension scores in the average range or above. 
Research on reading comprehension in ASD is largely descriptive and few studies have probed factors that explain individual differences in reading in this group. However, there are some data that indicate a relationship between oral language and reading comprehension in ASD. Nation et al. (2006) reported a strong correlation between reading comprehension and measures of oral language. This is consistent with Lindgren et al. (2009), who subdivided children and adolescents with ASD into those with and without concomitant language impairments and compared them to children with SLI. The two groups of children with impaired language obtained equivalent reading comprehension scores, whereas the group of children with ASD but unimpaired language scored significantly higher. There is also evidence from a regression model that oral language explains variance in reading comprehension after controlling for word recognition (Norbury \& Nation, in press). Further, Nation et al. (2006) showed that when poor and skilled comprehenders with ASD were compared, the skilled comprehenders obtained significantly higher oral language comprehension scores despite the groups being matched on word recognition.

Norbury and Nation (in press) described ASD groups with and without language impairments and compared them to typically developing peers. The language impaired ASD group showed significantly lower reading comprehension than the control group. However, the adolescents with ASD but no language impairment performed at an intermediate level and did not differ significantly from either group. Therefore, reading comprehension does not perfectly align with language status. This raises the possibility that the social and communication impairments that are characteristic of ASD may play a role in determining reading comprehension abilities. In support of this, Jones et al. (2009) reported a significant correlation between the severity of social and communication impairment (as measured by the Autism Diagnostic Observation Schedule; Lord et al., 2000) and an index of reading comprehension (the discrepancy between reading comprehension and full-scale IQ). 
The correlation between social interaction and communication and reading comprehension could reflect a causal relationship such that social and communicative deficits constrain the ability to construct a mental representation of a text so that it can be fully understood (cf. Norbury \& Nation, in press; O'Connor \& Klein, 2004). For instance, a core deficit in understanding the mental states of others (e.g., Baron-Cohen, 2000) may impact on the ability to process the intentions and desires of protagonists in a narrative text. White et al. (2009) have suggested that processing animate agents may be difficult for individuals with ASD even when mental state attributions are not necessary. Since narrative texts typically involve mental state attribution or animacy of some sort, they may be particularly difficult for individuals with ASD. In addition, across types of text (e.g., narrative, expository), weak central coherence (Frith, 2003) could impact on the ability to use context to make inferences and integrate parts of a text.

While impaired social interaction and communication is intrinsic to ASD, reading comprehension difficulties are not universal (Nation et al., 2006). An alternative explanation for the correlation between these variables may be that oral language skills determine performance on both ADOS and reading measures, such that the correlation simply reflects the well-established relationship between oral language and reading. Norbury and Nation (in press) entered a group variable (ASD vs. typically developing) into a regression model after controlling for the variance explained by word recognition and oral language. Group did not explain additional variance in reading comprehension as measured using a standardised test but it did explain variance in inferencing, a central comprehension process (Perfetti, Landi, \& Oakhill, 2005). Given this inconclusive finding, a fruitful area for future research would be to systematically explore ASD characteristics and relationships with oral language and reading comprehension. 
In conclusion, a small number of fairly large-scale studies have explored reading comprehension in ASD and show that this aspect of reading is an area of weakness for many, but not all individuals. Further, reading comprehension is predicted by both word recognition and oral language, indicating that models of reading based on typical patterns of development can be applied to this group (cf. Nation \& Norbury, 2005). However, the studies reviewed here include samples of relatively high functioning children and adolescents - where reported, mean scores for performance IQ or nonverbal ability are in the average range. Therefore, it is not clear how well we can generalise from the data that are available; in particular, studies may overestimate average reading skills in ASD. In addition, longitudinal data tracking reading comprehension development in ASD are entirely lacking. Appropriately designed longitudinal studies could address a number of important questions pertaining to reading comprehension in ASD. For example, the extent to which oral language weaknesses are a cause or consequence of reading comprehension failure (Nation et al., 2010) and the factors that support good reading in a small subgroup (cf. Nation et al., 2006).

\section{Methodological issues}

Reading comprehension is difficult to measure as it is not a unitary construct and involves a number of cognitive processes that cannot be directly observed. Therefore, there are a number of methodological issues that should be taken into consideration when interpreting reading comprehension research. Assessments typically require individuals to read connected text and then demonstrate their understanding. Beyond this, the exact nature of the tests varies enormously. Texts can be short or long, narrative or expository and some are read silently whereas others are read aloud. Where passages are read aloud, it is possible for the tester to correct reading errors, making measurement of reading accuracy and comprehension more independent. Different response formats can be used to assess comprehension; these include cloze, multiple-choice, true-false judgments, sentence 
completion, open-ended questions and story-retell. Irrespective of format, the nature of the question varies substantially, with some items being more or less dependent on word recognition, specific vocabulary, background knowledge and the particular type of inference required.

The nature of the assessment will determine which aspects of comprehension are being measured and which children are identified as having reading comprehension impairments. Performance on some reading comprehension tests appears to be highly dependent on word recognition. Keenan et al. (2008) compared a number of popular assessments used clinically in the US. Correlations among measures were modest, indicating that they are not equivalent. Further, factor analyses and regression models indicated that while some measures were reliant on oral language comprehension, performance on others was largely determined by word recognition (for similar findings, see Cutting \& Scarborough, 2006; Nation \& Snowling, 1997; Spooner, Baddeley, \& Gathercole, 2004). Reading comprehension measures also vary in terms of the types of questions that are asked e.g., whether a correct response requires literal understanding or for inferences to be made (Bowyer-Crane \& Snowling, 2005). It follows that reading comprehension impairments may be overestimated in children who have difficulty reading words or making inferences. As described above, word recognition difficulties are common in SLI, DS and ASD. Further, making inferences may be an area of particular weakness in ASD (Norbury \& Bishop, 2002; but see Saldaña \& Frith, 2007).

It is worth noting that many children with SLI, DS and ASD have difficulties with articulation and limited expressive language. With one exception (Laws \& Gunn, 2002), all of the studies on reading in SLI, DS and ASD summarised above have employed assessments that require a verbal response, an outcome measure that will likely underestimate reading comprehension in children with expressive language difficulties. Laws \& Gunn (2002) 
utilised a task in which children with DS acted out written instructions. An equivalent measure - or one where children make a written response - may be useful in future studies of reading comprehension in children with limited expressive language.

\section{Implications of poor reading comprehension}

As children move from 'learning to read' in early childhood to 'reading to learn' as adolescents and adults, reading comprehension will increasingly determine how well they access the school curriculum and information more generally (cf. Cain \& Oakhill, 2006). Since the majority of children with SLI, DS and ASD are at risk for reading comprehension difficulties in addition to their impairments in language and/or communication, it is very likely that their learning and educational achievement will be compromised and that many will experience difficulties with everyday tasks in adulthood (e.g., reading and completing application forms) and with finding employment (Conti-Ramsden, Durkin, Simkin, \& Knox, 2009; Dockrell, Lindsay, Palikara, \& Cullen, 2007; Howlin, Mawhood, \& Rutter, 2000; Whitehouse, Watt, Line, \& Bishop, 2009).

Intervention that is targeted at improving reading comprehension skills, as well as other areas of weakness, may improve educational attainment and life choices for children with developmental disorders. However, the evidence base for reading comprehension interventions is relatively small (see Duff \& Clarke, 2011 for a recent review of existing studies). Nonetheless, there is evidence for successful intervention for poor comprehenders (Clarke et al., 2010; Johnson-Glenberg, 2005; Yuill \& Oakhill, 1988) and children with DS (Morgan, Moni, \& Jobling, 2004) and ASD (O'Connor \& Klein, 2004).

Given that language comprehension difficulties are implicated in the reading comprehension difficulties observed in children with SLI, DS and ASD (e.g., Bishop \& Snowling, 2004; Norbury \& Nation, in press; Roch et al., in press), it seems likely that oral language training would benefit reading comprehension in these children. However, language 
profiles in these groups are heterogeneous and research on SLI, DS and ASD has done little to systematically explore specific relationships between aspects of oral language and reading comprehension (for an exception, see Bishop \& Snowling, 2004). Different intervention approaches may be required to support reading comprehension, depending on the specific language profile observed in a child or group of children. For example, difficulties with figurative language are common in ASD (Bishop \& Norbury, 2002; Norbury, 2005), indicating that this aspect of language should be particularly emphasised. Similarly, many children with DS experience greater difficulty with syntactic than lexical tasks (e.g., Chapman, 1997) again suggesting how intervention efforts might be best targeted. Future research should aim to explore whether and how intervention programmes should be tailored to improve reading comprehension in children with different cognitive profiles.

As literacy skills develop, the activity of reading may foster oral language and word recognition skills. For example, the reading process provides an opportunity for children to build both oral and sight vocabularies (e.g., Nagy, Herman, \& Anderson, 1985). However, children with word recognition and reading comprehension impairments are less likely to learn new words (Aguiar \& Brady, 1991; Cain, Oakhill, \& Elbro, 2003; Ricketts, Bishop, \& Nation, 2008). Therefore, reading difficulties may constrain word recognition and oral vocabulary development in children with SLI, DS and ASD. There is some evidence for this in ASD. In their study of adolescents with ASD, Norbury and Nation (in press) observed a decline in word reading standard scores over a period of four years and posited that this reflected poor reading comprehension. However, this proposal was not tested systematically and should therefore be treated as preliminary, not least because poor reading comprehension did not always correspond to a notable reduction in word reading score (language impaired ASD group), reading comprehension was not assessed over time and change in word recognition was not reported for their comparison group. It is worth noting that in DS, the 
discrepancy between word recognition and reading comprehension appears to increase with age such that word reading improves over time but reading comprehension does not (e.g., Byrne et al., 2002). Therefore, poor reading comprehension may impact less (or not at all) on word recognition development in this group.

More broadly, just as supporting oral language skills might improve the comprehension of texts for children with language difficulties, teaching reading skills could also promote language outcomes for these children. Surprisingly advanced reading relative to oral language has been reported in DS (Groen et al., 2006; Roch \& Levorato, 2009), ASD (Newman et al., 2007) and SLI (Bishop et al., 2009). Therefore, it seems plausible that relative strengths in reading could be harnessed to promote oral language development. Laws and Gunn (2002) investigated this hypothesis in DS. Over five years, reading comprehension predicted language production (but not comprehension), after taking both age and nonverbal ability into account. However, these findings are difficult to interpret as language production was not assessed at time 1 . Thus, readers may have had better expressive language at the outset (see also Laws, Buckley, Bird, MacDonald, \& Broadly, 1995). Further, the question of whether reading could support language development has not been investigated in SLI and ASD.

This issue warrants further investigation. As well as being of theoretical interest, it has clear practical implications. If it could be shown that teaching reading promotes language development then this could provide a powerful tool for education professionals. A related possibility is that for some children (i.e., those with reading in advance of language), reading texts may provide a better context for learning than listening to oral language. One obvious difference between the processing demands of oral and written language is in timing - while spoken signals are transient, texts are typically available for an extended period of time. Therefore, processing written language might be easier because it places different demands on memory and there are strategies that can be applied to written texts (e.g., re-reading) that 
are impossible while listening. In addition, reading and writing are arguably less social tasks than listening and conversing - and thus potentially more accessible to children with ASD. Clearly, additional data are needed. An essential first step in this line of research would be to establish whether the comprehension of written material is better than listening comprehension in SLI, DS and/or ASD using appropriately matched reading and listening tasks (for an attempt at this, Roch \& Levorato, 2009). Further, longitudinal data exploring the changing relationship between reading and language and carefully designed intervention studies could provide convincing evidence for emphasising the use of written language in teaching materials.

\section{Beyond the Simple View of Reading}

The Simple View of Reading has been used as a framework for illustrating individual differences in reading in children with and without developmental disorders (e.g., Bishop \& Snowling, 2004; Catts et al., 2006; Nation \& Norbury, 2005; Roch \& Levorato, 2009). There are a number of advantages of the Simple View. Most importantly, the model considers abilities beyond single word reading that contribute to skilled reading and in doing so emphasises the role of oral language. Despite taking a broader view of reading, the model is parsimonious and its principles can be readily communicated to professionals outside of the research community (e.g., Gough et al., 1996; Savage, 2006). It has clear practical implications in highlighting the need to consider both word recognition and comprehension, and to target both in teaching and intervention. Indeed, the Simple View of Reading has guided educational policy in the UK (Stuart, Stainthorp, \& Snowling, 2008). Although the model itself is simple and accessible, its proponents take care to note that learning to read is not simple but rather involves the development of a complex array of abilities (Kirby \& Savage, 2008; Stuart et al., 2008). 
Since its inception, the Simple View of Reading has been evaluated by a number of studies and its basic premises have been well supported. There is overwhelming evidence that both word recognition and language comprehension account for unique variance in skilled reading (e.g., Adlof, Catts, \& Little, 2006; Chen \& Vellutino, 1997; Gough et al., 1996). The model's application to DS may be challenged by two studies of Italian adolescents with DS in which oral language but not word recognition uniquely predicted reading comprehension (Roch et al., in press; Roch \& Levorato, 2009). However, interpretation of one of these studies is limited by small sample size (Roch et al., in press) and the studies are somewhat at odds with studies of English-speaking DS individuals (Byrne et al., 2002; Cardoso-Martins et al., 2009). It is also worth noting that the roles of word recognition and language in predicting reading comprehension are moderated by age and word recognition skill (Chen \& Vellutino, 1997; Gough et al., 1996), and will depend on the reading comprehension assessment used (e.g., Keenan et al., 2008).

The assumption that word recognition and language comprehension are relatively independent is supported by analytic approaches (e.g., Savage, 2006), behavioural genetic studies (Byrne et al., 2009; Harlaar et al., 2010; Keenan et al., 2006) and data from typically developing readers (e.g., Muter et al., 2004; Oakhill et al., 2003) and the existence of children with specific reading difficulties (dyslexia, poor comprehenders). Additional evidence comes from the observation of dissociations between word recognition and reading comprehension in SLI, DS and ASD as described above. Nonetheless, substantial correlations between the components (e.g., Chen \& Vellutino, 1997; Nation et al., 2006; Savage, 2006) indicate that the independence must not be overstated. There is also mounting evidence that semantic knowledge (as indexed by oral vocabulary tasks) predicts word recognition as well as reading comprehension (Kirby \& Savage, 2008; Nation \& Snowling, 2004; Ouellette \& Beers, 2010; Ricketts, Nation, \& Bishop, 2007) - further evidence for a degree of overlap. 
If the Simple View of Reading is taken as a complete model of skilled reading then once word recognition skills have been accounted for, reading and language comprehension should be indistinguishable (cf. Adlof et al., 2006). Multiple regression analyses indicate that the combination of word recognition and language comprehension does indeed explain a large amount of variance in reading comprehension but a substantial amount remains unaccounted for (e.g., Chen \& Vellutino, 1997; Cutting \& Scarborough, 2006; Keenan et al., 2008). This unexplained variance will likely reflect differences between reading and oral language comprehension - such as the differences in timing discussed above (Gough et al., 1996; Kirby \& Savage, 2008) - and knowledge or skills beyond word recognition and language comprehension that support reading comprehension.

There has been little exploration of factors beyond word recognition and listening comprehension that determine reading success. Reading fluency has perhaps received the most attention but the evidence is mixed (Adlof et al., 2006; Cutting \& Scarborough, 2006; Johnston \& Kirby, 2006; Joshi \& Aaron, 2000) and this variable may be best considered a part of the word recognition component rather than an additional predictor (cf. Perfetti, 1985). In addition, consideration of reading comprehension in children with language impairments highlighted a role for nonverbal ability (see above). This variable may also be relevant to children with DS and ASD, many of whom exhibit nonverbal deficits.

Working memory has also been invoked as a possible cause of reading comprehension failure (Cain, 2006) suggesting that this might be an important factor in reading, beyond the components of the Simple View. Working memory impairments have been reported in SLI, DS and ASD (Baddeley \& Jarrold, 2007; Gathercole \& Alloway, 2006; Joseph, McGrath, \& Tager-Flusberg, 2005; Russell, Jarrold, \& Henry, 1996) as well as in poor comprehenders (Nation, Adams, Bowyer-Crane, \& Snowling, 1999; Pimperton \& Nation, 2010; Yuill, Oakhill, \& Parkin, 1989) and there is evidence from typically developing children that 
performance on working memory tasks predicts reading comprehension both concurrently and longitudinally (e.g., Oakhill et al., 2003). Thus, working memory and reading comprehension impairments may be associated in SLI, DS and ASD. However, the precise role of working memory in explaining reading comprehension impairments remains controversial. Cain (2006) has suggested that working memory impairments may underpin difficulties with discourse-level processes (e.g., making inferences), which in turn give rise to poor reading comprehension. In contrast, Nation and colleagues (1999) showed that poor comprehenders' working memory impairments were restricted to the verbal domain and concluded that the relationship between working memory and reading comprehension is indirect such that poor verbal abilities constrain performance on both types of task (see also Pimperton \& Nation, 2010; Stothard \& Hulme, 1992).

Two further limitations of the Simple View should be noted. First, the model is static and therefore its application to developmental disorders is limited. Second, a number of researchers have argued that the word recognition and language comprehension elements of the Simple View are not well defined. Ouellette and Beers (2010) noted the confusion surrounding the word recognition component. Indeed, in some studies it is defined narrowly as 'decoding' (direct translation between spelling and sound) and assessed using nonword reading tasks (Gough \& Tunmer, 1986; Joshi \& Aaron, 2000) and in others a wider definition is adopted and various measures of nonword, word and text reading are used (Chen \& Vellutino, 1997; Ouellette \& Beers, 2010; Savage, 2006). Although in some studies the pattern of results is consistent across measures of nonword and word reading, Ouellette and Beers (2010) showed that both nonword and word reading make unique contributions to reading comprehension, indicating that both should be considered in the word recognition component. This is perhaps more relevant for opaque languages such as English where translating directly from spelling to sound is not sufficient to read all words (i.e., irregularly 
spelled words such as yacht and island) than for transparent languages such as Italian and Finnish where the majority can be decoded effectively (cf. Share, 2008).

The language comprehension component is often measured using global listening comprehension or a composite of tasks tapping language domains (e.g., vocabulary, grammar). Assessing language in this way may mask the subtleties of the relationship between oral language and reading comprehension. Ouellette and Beers (2010) have reported evidence that vocabulary may have a particularly prominent role to play, showing that after controlling for word recognition and listening comprehension, a measure of vocabulary breadth predicted significant variance in reading comprehension in children aged 11-12 years (see also Savage, 2006). However, Stuart et al. (2008) note that although vocabulary is a strong and important predictor of reading comprehension, children can fail to understand texts after this is controlled for (Cain et al., 2003) indicating that processes beyond the lexical are also important.

In sum, although the Simple View of Reading has many advantages and has informed policy and practice in the UK (Stuart et al., 2008), a number of limitations of the framework have been highlighted. Of particular relevance here is that research on reading comprehension difficulties highlights nonverbal ability and working memory as factors beyond word recognition and language comprehension that impact on reading comprehension development. Elaboration of the model may enhance its value to researchers and educational professionals, for instance by indicating that supporting working memory could promote reading comprehension.

\section{Conclusions}

For more than a decade, there has been a focus on highlighting associations as well as dissociations amongst developmental disorders (Bishop, 1997; Karmiloff-Smith, 1997). SLI, DS and ASD are characterised by different cognitive and behavioural profiles. Nonetheless, 
in all groups, reading comprehension is typically an area of weakness and a discrepancy between component reading skills is usually observed, with impaired reading comprehension relative to more advanced word recognition. Consequently, there has been interest in potential overlap between poor comprehenders and children with SLI (Catts et al., 2006; Nation et al., 2004), DS (Groen et al., 2006) and ASD (Nation \& Norbury, 2005). However, in contrast to the circumscribed poor comprehender profile, considerable individual differences in word recognition and comprehension have been reported in SLI, DS and ASD. Particularly surprising is the observation that age-appropriate word recognition and reading comprehension can occur in children with ASD and a history of SLI. There has been recent interest in comorbidity between SLI and ASD, especially in relation to language (Bishop, 2010; Kjelgaard \& Tager-Flusberg, 2001; Williams, Botting, \& Boucher, 2008) and literacy (Lindgren et al., 2009). However, overlap between these groups appears to be limited to children who currently have language impairments.

\section{Key points}

- Many children with specific language impairment (SLI), Down syndrome (DS) and autism spectrum disorders (ASD) have very limited or no reading skills.

- For children who can read, comprehension appears to be a particular area of weakness relative to word recognition.

- Reading that is more advanced than oral language has been reported in some children with SLI, DS and ASD. Further, age-appropriate word recognition and reading comprehension can occur in children with ASD and a history of SLI.

- Language comprehension difficulties are implicated in the reading comprehension impairments observed in ALI, DS and ASD but other factors such as nonverbal ability, hearing, social understanding and working memory may also play a role. 


\section{References}

Adlof, S., Catts, H., \& Little, T. (2006). Should the Simple View of Reading Include a Fluency Component? Reading and Writing, 19(9), 933-958.

Aguiar, L., \& Brady, S. (1991). Vocabulary acquisition and reading ability. Reading and Writing, 3(3-4), 413-425.

Baddeley, A., \& Jarrold, C. (2007). Working memory and Down syndrome. Journal of Intellectual Disability Research, 51(12), 925-931.

Baird, G., Simonoff, E., Pickles, A., Chandler, S., Loucas, T., Meldrum, D., et al. (2006). Prevalence of disorders of the autism spectrum in a population cohort of children in South Thames: the Special Needs and Autism Project (SNAP). The Lancet, 368(9531), 210-215.

Baron-Cohen, S. (2000). Theory of mind and autism: A review. In G. Laraine Masters (Ed.), International Review of Research in Mental Retardation (Vol. Volume 23, pp. 169184): Academic Press.

Besser, L., Shin, M., Kucik, J., \& Correa, A. (2007). Prevalence of down syndrome among children and adolescents in metropolitan Atlanta. Birth Defects Research Part A: Clinical and Molecular Teratology, 79(11), 765-774.

Bishop, D. V. M. (1997). Neuropsychology and developmental disorders: Uncomfortable bedfellows. The Quarterly Journal of Experimental Psychology, 50A, 899-923.

Bishop, D. V. M. (2010). Overlaps between autism and language impairment: Phenomimicry or shared etiology? Behavior Genetics, 40(5), 618-629.

Bishop, D. V. M., \& Adams, C. (1990). A Prospective Study of the Relationship between Specific Language Impairment, Phonological Disorders and Reading Retardation. Journal of Child Psychology and Psychiatry, 31(7), 1027-1050. 
Bishop, D. V. M., \& Edmundson, A. (1987). Language-Impaired 4-Year-Olds:

Distinguishing Transient from Persistent Impairment. J Speech Hear Disord, 52(2), $156-173$

Bishop, D. V. M., McDonald, D., Bird, S., \& Hayiou-Thomas, M. E. (2009). Children Who Read Words Accurately Despite Language Impairment: Who Are They and How Do They Do It? Child Development, 80(2), 593-605.

Bishop, D. V. M., \& Norbury, C. F. (2002). Exploring the borderlands of autistic disorder and specific language impairment: a study using standardised diagnostic instruments. Journal of Child Psychology and Psychiatry and Allied Disciplines, 43(7), 917-929.

Bishop, D. V. M., \& Snowling, M. J. (2004). Developmental dyslexia and specific language impairment: Same or different? Psychological Bulletin, 130(6), 858-886.

Botting, N., Simkin, Z., \& Conti-Ramsden, G. (2006). Associated Reading Skills in Children with a History of Specific Language Impairment (SLI). Reading and Writing, 19(1), 77-98.

Boudreau, D. (2002). Literacy skills in children and adolescents with Down syndrome. Reading and Writing, 15(5), 497-525.

Bowyer-Crane, C. A., \& Snowling, M. J. (2005). Assessing children's inference generation: What do tests of reading comprehension measure? British Journal of Educational Psychology, 75(2), 189-201.

Byrne, A., MacDonald, J., \& Buckley, S. (2002). Reading, language and memory skills: A comparative longitudinal study of children with Down syndrome and their mainstream peers. British Journal of Educational Psychology, 72, 513-529.

Byrne, B., Coventry, W. L., Olson, R. K., Samuelsson, S., Corley, R., Willcutt, E. G., et al. (2009). Genetic and environmental influences on aspects of literacy and language in 
early childhood: Continuity and change from preschool to Grade 2. Journal of Neurolinguistics, 22(3), 219-236.

Cain, K. (2006). Children's reading comprehension: The role of working memory in normal and impaired development. In S. Pickering (Ed.), Working memory and education (pp. 62-93). New York: Academic Press.

Cain, K., \& Oakhill, J. (2006). Profiles of children with specific reading comprehension difficulties. British Journal of Educational Psychology, 76, 683-696.

Cain, K., \& Oakhill, J. (2007). Children's comprehension problems in oral and written language: A cognitive perspective. New York: Guildford Press.

Cain, K., Oakhill, J., \& Elbro, C. (2003). The ability to learn new word meanings from context by school-age children with and without language comprehension difficulties. Journal of Child Language, 30, 681-694.

Cardoso-Martins, C., Peterson, R., Olson, R., \& Pennington, B. (2009). Component reading skills in Down Syndrome. Reading and Writing, 22(3), 277-292.

Carroll, J. M., \& Snowling, M. J. (2004). Language and phonological skills in children at high risk of reading difficulties. Journal of Child Psychology and Psychiatry, 45(3), 631-640.

Catts, H. W., Adlof, S. M., Hogan, T., \& Weismer, S. E. (2005). Are specific language impairment and dyslexia distinct disorders? Journal of Speech Language and Hearing Research, 48(6), 1378-1396.

Catts, H. W., Adlof, S. M., \& Weismer, S. E. (2006). Language deficits in poor comprehenders: A case for the simple view of reading. Journal of Speech, Language, and Hearing Research, 49, 278-293. 
Catts, H. W., Bridges, M. S., Little, T. D., \& Tomblin, J. B. (2008). Reading Achievement Growth in Children With Language Impairments. Journal of Speech, Language and Hearing Research, 51(6), 1569-1579.

Catts, H. W., Fey, M. E., Tomblin, J. B., \& Zhang, X. (2002). A Longitudinal Investigation of Reading Outcomes in Children With Language Impairments. Journal of Speech, Language and Hearing Research, 45(6), 1142-1157.

Chapman, R. S. (1997). Language development in children and adolescents with Down syndrome. Mental Retardation and Developmental Disabilities Research Reviews, 3(4), 307-312.

Chen, R. S., \& Vellutino, F. R. (1997). Prediction of reading ability: A cross-validation study of the simple view of reading. Journal of Literacy Research, 29(1), 1 - 24.

Clarke, P. J., Snowling, M. J., Truelove, E., \& Hulme, C. (2010). Ameliorating children's reading comprehension difficulties: A randomised controlled trial. Psychological Science, 21, 1106-1116.

Conti-Ramsden, G., Durkin, K., Simkin, Z., \& Knox, E. (2009). Specific language impairment and school outcomes. I: Identifying and explaining variability at the end of compulsory education. International Journal of Language \& Communication Disorders, 44(1), 15-35.

Cutting, L. E., \& Scarborough, H. S. (2006). Prediction of reading comprehension: Relative contributions of word recognition, language proficiency, and other cognitive skills can depend on how comprehension is measured. Scientific Studies of Reading, 10(3), 277299.

Dockrell, J. E., Lindsay, G., Palikara, O., \& Cullen, M. (2007). Raising the achievements of children and young people with specific speech and language difficulties and 
communication needs and other special educational needs through school, to work and college. Nottingham, England: Department for Education and Skills.

Duff, F. J., \& Clarke, P. J. (2011). Practitioner review: Reading disorders: what are the effective interventions and how should they be implemented and evaluated? Journal of Child Psychology and Psychiatry, 52(1), 3-12.

Field, A. (2005). Discovering Statistics Using SPSS (2nd ed.). London: Sage Publications Ltd.

Frith, U., \& Snowling, M. (1983). Reading for meaning and reading for sound in autistic and dyslexic children. British Journal of Developmental Psychology, 1, 329-342.

Gathercole, S., \& Alloway, T. (2006). Practitioner Review: Short-term and working memory impairments in neurodevelopmental disorders: diagnosis and remedial support. Journal of Child Psychology and Psychiatry, 47(1), 4-15.

Gough, P. B., Hoover, W. A., \& Peterson, C. L. (1996). Some observations on a simple view of reading. In C. Cornoldi \& J. Oakhill (Eds.), Reading comprehension difficulties: Processes and intervention (pp. 1-13). Mahwah, NJ: Erlbaum.

Gough, P. B., \& Tunmer, W. E. (1986). Decoding, reading, and reading disability. Remedial and Special Education, 7, 6-10.

Grigorenko, E. L., Klin, A., \& Volkmar, F. (2003). Annotation: Hyperlexia: disability or superability? Journal of Child Psychology and Psychiatry, 44(8), 1079-1091.

Groen, M. A., Laws, G., Nation, K., \& Bishop, D. V. M. (2006). A case of exceptional reading accuracy in a child with Down syndrome: Underlying skills and the relation to reading comprehension. Cognitive Neuropsychology, 23(8), 1190 - 1214.

Happé, F. (1999). Autism: Cognitive deficit or cognitive style? Trends in Cognitive Sciences, 3(6), 216-222. 
Harlaar, N., Cutting, L., Deater-Deckard, K., DeThorne, L. S., Justice, L. M., Schatschneider, C., et al. (2010). Predicting individual differences in reading comprehension: a twin study. Annals of Dyslexia, 60(2), 265-288.

Hatcher, P. J., Hulme, C., Miles, J. N., Carroll, J. M., Hatcher, J., Gibbs, S., et al. (2006). Efficacy of small group reading intervention for beginning readers with readingdelay: a randomised controlled trial. Journal of Child Psychology and Psychiatry, 47(8), 820-827.

Howlin, P., Mawhood, L., \& Rutter, M. (2000). Autism and Developmental Receptive Language Disorder - a Follow-up Comparison in Early Adult Life. II: Social, Behavioural, and Psychiatric Outcomes. The Journal of Child Psychology and Psychiatry and Allied Disciplines, 41(05), 561-578.

Hulme, C., \& Snowling, M. J. (2009). Developmental disorders of language learning and cognition. Oxford, UK: Wiley-Blackwell.

Johnson-Glenberg, M. C. (2005). Web-based training of metacognitive strategies for text comprehension: Focus on poor comprehenders. Reading and Writing, 18, 755-786.

Johnston, T., \& Kirby, J. (2006). The Contribution of Naming Speed to the Simple View of Reading. Reading and Writing, 19(4), 339-361.

Jones, C. R. G., Happé, F., Golden, H., Marsden, A. J. S., Tregay, J., Simonoff, E., et al. (2009). Reading and arithmetic in adolescents with autism spectrum disorders: Peaks and dips in attainment. Neuropsychology, 23(6), 718-728.

Joseph, R. M., McGrath, L. M., \& Tager-Flusberg, H. (2005). Executive Dysfunction and Its Relation to Language Ability in Verbal School-Age Children With Autism. Developmental Neuropsychology, 27(3), 361 - 378.

Joshi, R. M., \& Aaron, P. G. (2000). The component model of reading: Simple view of reading made a little more complex. Reading Psychology, 21(2), 85 - 97. 
Karmiloff-Smith, A. (1997). Crucial differences between developmental cognitive neuroscience and adult neuropsychology. Developmental Neuropsychology, 13, 513524.

Kay-Raining Bird, E., \& Chapman, R. S. (in press). Literacy development in childhood, adolescence, and young adulthood in persons with Down syndrome. In J. A. Burack, R. M. Hodapp \& E. F. Zigler (Eds.), Handbook of Mental Retardation and Development (2nd ed.). Oxford, UK: Oxford University Press.

Keenan, J. M., Betjemann, R. S., \& Olson, R. K. (2008). Reading comprehension tests vary in the skills they assess: Differential dependence on decoding and oral comprehension. Scientific Studies of Reading, 12(3), 281 - 300.

Keenan, J. M., Betjemann, R. S., Wadsworth, S. J., DeFries, J. C., \& Olson, R. K. (2006). Genetic and environmental influences on reading and listening comprehension. Journal of Research in Reading, 29(1), 75-91.

Kirby, J., \& Savage, R. (2008). Can the simple view deal with the complexities of reading? Literacy, 42(2), 75-82.

Kjelgaard, M. M., \& Tager-Flusberg, H. (2001). An investigation of language impairment in autism: Implications for genetic subgroups. Language and cognitive processes, 16(2/3), 287-308.

Laws, G., Buckley, S., Bird, G., MacDonald, J., \& Broadly, I. (1995). The influence of reading instruction on language and memory development in children with Down's syndrome. Down's Syndrome: Research and Practice, 3, 59-64.

Laws, G., \& Gunn, D. (2002). Relationships between reading, phonological skills and language development in individuals with Down syndrome: A five year follow-up study. Reading and Writing, 15(5-6), 527-548. 
Lindgren, K. A., Folstein, S. E., Tomblin, J. B., \& Tager-Flusberg, H. (2009). Language and reading abilities of children with autism spectrum disorders and specific language impairment and their first-degree relatives. Autism Research, 2(1), 22-38.

Lord, C., Risi, S., Lambrecht, L., Cook, E. H., Leventhal, B. L., DiLavore, P. C., et al. (2000). The Autism Diagnostic Observation Schedule - Generic: A Standard Measure of Social and Communication Deficits Associated with the Spectrum of Autism. Journal of Autism and Developmental Disorders, 30(3), 205-223.

Mervis, C. B. (2009). Language and literacy development of children with Williams syndrome. Topics in Language Disorders, 29(2), 149-169.

Morgan, M., Moni, K. B., \& Jobling, A. (2004). What's it all about? Investigating reading comprehension strategies in young adults with Down syndrome. Down Syndrome Research and Practice, 9(37-44).

Muter, V., Hulme, C., Snowling, M. J., \& Stevenson, J. (2004). Phonemes, rimes, vocabulary, and grammatical skills as foundations of early reading development: Evidence from a longitudinal study. Developmental psychology, 40(5), 665-681.

Nagy, W., Herman, P. A., \& Anderson, R. C. (1985). Learning words from context. Reading Research Quarterly, 20(2), 233-253.

Nation, K. (1999). Reading skills in hyperlexia: A developmental perspective. Psychological Bulletin, 125(3), 338-355.

Nation, K. (2005). Children's reading comprehension difficulties. In M. J. Snowling, C. Hulme \& M. Seidenberg (Eds.), The science of reading: A handbook (pp. 248-265). Oxford: Blackwell.

Nation, K., Adams, J. W., Bowyer-Crane, C. A., \& Snowling, M. J. (1999). Working memory deficits in poor comprehenders reflect underlying language impairments. Journal of Experimental Child Psychology, 73, 139-158. 
Nation, K., Clarke, P., Marshall, C. M., \& Durand, M. (2004). Hidden language impairments in children: Parallels between poor reading comprehension and specific language impairment. Journal of Speech, Language, and Hearing Research, 47, 199-211.

Nation, K., Clarke, P., \& Snowling, M. J. (2002). General cognitive ability in children with reading comprehension difficulties. British Journal of Educational Psychology, 72, 549-560.

Nation, K., Clarke, P., Wright, B., \& Williams, C. (2006). Patterns of reading ability in children with autism spectrum disorder. Journal of Autism and Developmental Disorders, 36, 911-919.

Nation, K., Cocksey, J., Taylor, J. S., \& Bishop, D. V. M. (2010). A longitudinal investigation of early reading and language skills in children with poor reading comprehension. Journal of Child Psychology and Psychiatry, 51(9), 1031-1039.

Nation, K., \& Norbury, C. F. (2005). When reading comprehension fails: Insights from developmental disorders. Topics in Language Disorders, 25(1), 21-32.

Nation, K., \& Snowling, M. J. (1997). Assessing reading difficulties: The validity and utility of current measures of reading skill. British Journal of Educational Psychology, 67, 359-370.

Nation, K., \& Snowling, M. J. (1998). Individual differences in contextual facilitation: Evidence from dyslexia and poor reading comprehension. Child Development, 69(4), 996-1011.

Nation, K., \& Snowling, M. J. (2004). Beyond phonological skills: Broader language skills contribute to the development of reading. Journal of Research in Reading, 27, 342356.

National Institute of Child Health and Human Development, National Reading Panel. (2000). Teaching children to read: An evidence based assessment of the scientific research 
literature on reading and its implications for reading instruction. Retrieved June 2, 2010, from http://www.nichd.nih.gov/publications/nrp/smallbook.cfm

Newman, T. M., Macomber, D., Naples, A. J., Babitz, T., Volkmar, F., \& Grigorenko, E. L. (2007). Hyperlexia in children with Autism Spectrum Disorders. Journal of Autism and Developmental Disorders, 37(4), 760-774.

Norbury, C. (2005). The relationship between theory of mind and metaphor: Evidence from children with language impairment and autistic spectrum disorder. British Journal of Developmental Psychology, 23, 383-399.

Norbury, C., \& Bishop, D. V. M. (2002). Inferential processing and story recall in children with communication problems: A comparison of specific language impairment, pragmatic language impairment and high-functioning autism. International Journal of Language \& Communication Disorders, 37, 227-251.

Norbury, C., \& Nation, K. (in press). Understanding variability in reading comprehension in adoescents with autism spectrum disorders: Interactions with language status and decoding skill. Scientific Studies of Reading.

O'Connor, I., \& Klein, P. (2004). Exploration of strategies for facilitating the reading comprehension of high-functioning students with autism spectrum disorders. Journal of Autism and Developmental Disorders, 34(2), 115-127.

Oakhill, J., Cain, K., \& Bryant, P. (2003). The dissociation of word reading and text comprehension: Evidence from component skills. Language and cognitive processes, $18(4), 443-468$.

Ouellette, G., \& Beers, A. (2010). A not-so-simple view of reading: How oral vocabulary and visual-word recognition complicate the story. Reading and Writing, 23(2), 189-208. 
Palikara, O., Dockrell, J. E., \& Lindsay, G. (in press). Patterns of change in the reading decoding and comprehension performance of adolescents with specific language impairment (SLI). Learning Disabilities: A Contemporary Journal.

Perfetti, C. A. (1985). Reading ability. New York: Oxford University Press.

Perfetti, C. A., Landi, N., \& Oakhill, J. (2005). The acquisition of reading comprehension skill. In M. J. Snowling, C. Hulme \& M. Seidenberg (Eds.), The Science of Reading. Oxford, UK: Blackwell.

Pimperton, H., \& Nation, K. (2010). Suppressing irrelevant information from working memory: Evidence for domain-specific deficits in poor comprehenders. Journal of Memory and Language, 62(4), 380-391.

Ricketts, J., Bishop, D. V. M., \& Nation, K. (2008). Investigating orthographic and semantic aspects of word learning in poor comprehenders. Journal of Research in Reading, $31(1), 117-135$.

Ricketts, J., Nation, K., \& Bishop, D. V. M. (2007). Vocabulary is important for some, but not all reading skills. Scientific Studies of Reading, 11(3), 235-257.

Roch, M., Florit, E., \& Levorato, C. M. (in press). Follow-up study on reading comprehension in Down's syndrome: the role of reading skills and listening comprehension. International Journal of Language and Communication Disorders.

Roch, M., \& Jarrold, C. (2008). A comparison between word and nonword reading in Down syndrome: The role of phonological awareness. Journal of Communication Disorders, 41(4), 305-318.

Roch, M., \& Levorato, C. M. (2009). Simple View of Reading in Down's syndrome: The role of listening comprehension and reading skills. International Journal of Language \& Communication Disorders, 44(2), 206-223. 
Russell, J., Jarrold, C., \& Henry, L. (1996). Working Memory in Children with Autism and with Moderate Learning Difficulties. Journal of Child Psychology and Psychiatry, 37(6), 673-686.

Saldaña, D., Carreiras, M., \& Frith, U. (2009). Orthographic and Phonological Pathways in Hyperlexic Readers With Autism Spectrum Disorders. Developmental Neuropsychology, 34(3), 240 - 253.

Saldaña, D., \& Frith, U. (2007). Do readers with autism make bridging inferences from world knowledge? Journal of Experimental Child Psychology, 96(4), 310-319.

Savage, R. (2006). Reading comprehension is not always the product of nonsense word decoding and linguistic comprehension: Evidence from teenagers who are extremely poor readers. Scientific Studies of Reading, 10(2), 143-164.

Scarborough, H. S., \& Dobrich, W. (1990). Development of Children with Early Language Delay. Journal of Speech, Language, and Hearing Research, 33(1), 70-83.

Share, D. L. (2008). On the Anglocentricities of current reading research and practice: The perils of overreliance on an "outlier" orthography. Psychological Bulletin, 134(4), 584-615.

Snowling, M. (2000). Dyslexia (2nd ed.). Oxford, England: Blackwell.

Snowling, M., Bishop, D. V. M., \& Stothard, S. E. (2000). Is preschool language impairment a risk factor for dyslexia in adolescence? Journal of Child Psychology and Psychiatry and Allied Disciplines, 41(5), 587-600.

Spooner, A. L., Baddeley, A. D., \& Gathercole, S. E. (2004). Can reading accuracy and comprehension be separated in the Neale Analysis of Reading Ability? British Journal of Educational Psychology, 74, 187-204. 
Stothard, S. E., \& Hulme, C. (1992). Reading comprehension difficulties in children: The role of language comprehension and working memory skills. Reading and Writing, 4(245256).

Stothard, S. E., \& Hulme, C. (1995). A comparison of phonological skills in children with reading comprehension difficulties and children with decoding difficulties. Journal of Child Psychology and Psychiatry, 36(3), 399.

Stothard, S. E., Snowling, M. J., Bishop, D. V. M., Chipchase, B. B., \& Kaplan, C. A. (1998). Language-Impaired Preschoolers: A Follow-Up Into Adolescence. J Speech Lang Hear Res, 41(2), 407-418.

Stuart, M., Stainthorp, R., \& Snowling, M. (2008). Literacy as a complex activity: deconstructing the simple view of reading. Literacy, 42(2), 59-66.

Vellutino, F., Fletcher, J., Snowling, M., \& Scanlon, D. (2004). Specific reading disability (dyslexia): what have we learned in the past four decades? Journal of Child Psychology and Psychiatry, 45(1), 2-40.

White, S., Hill, E., Happé, F., \& Frith, U. (2009). Revisiting the Strange Stories: Revealing Mentalizing Impairments in Autism. Child Development, 80(4), 1097-1117.

Whitehouse, A. J. O., Watt, H. J., Line, E., \& Bishop, D. V. M. (2009). Adult psychosocial outcomes of children with specific language impairment, pragmatic language impairment and autism. International Journal of Language \& Communication Disorders, 44(4), 511-528.

Williams, D., Botting, N., \& Boucher, J. (2008). Language in autism and specific language impairment: Where are the links? Psychological Bulletin, 134(6), 944-963.

Yuill, N., \& Oakhill, J. (1988). Effects of inference awareness training on poor reading comprehension. Applied Cognitive Psychology, 2, 33-45. 
Yuill, N., \& Oakhill, J. (1991). Children's Problems in Text Comprehension: An Experimental Investigation. Cambridge: Cambridge University Press.

Yuill, N., Oakhill, J., \& Parkin, A. J. (1989). Working memory, comprehension ability and the resolution of text anomaly. British Journal of Psychology, 80(3), 351-361. 


\section{Author notes}

The author would like to thank Jo Taylor and Tony Charman for their helpful comments on an earlier draft of this paper.

Correspondence should be addressed to Jessie Ricketts, Centre for Educational Development, Appraisal and Research (CEDAR), University of Warwick, Coventry CV4 7AL, jessie.ricketts@warwick.ac.uk 
Ricketts/ 43

Figure captions

Figure 1. A multidimensional approach to skilled reading 
Ricketts/ 44

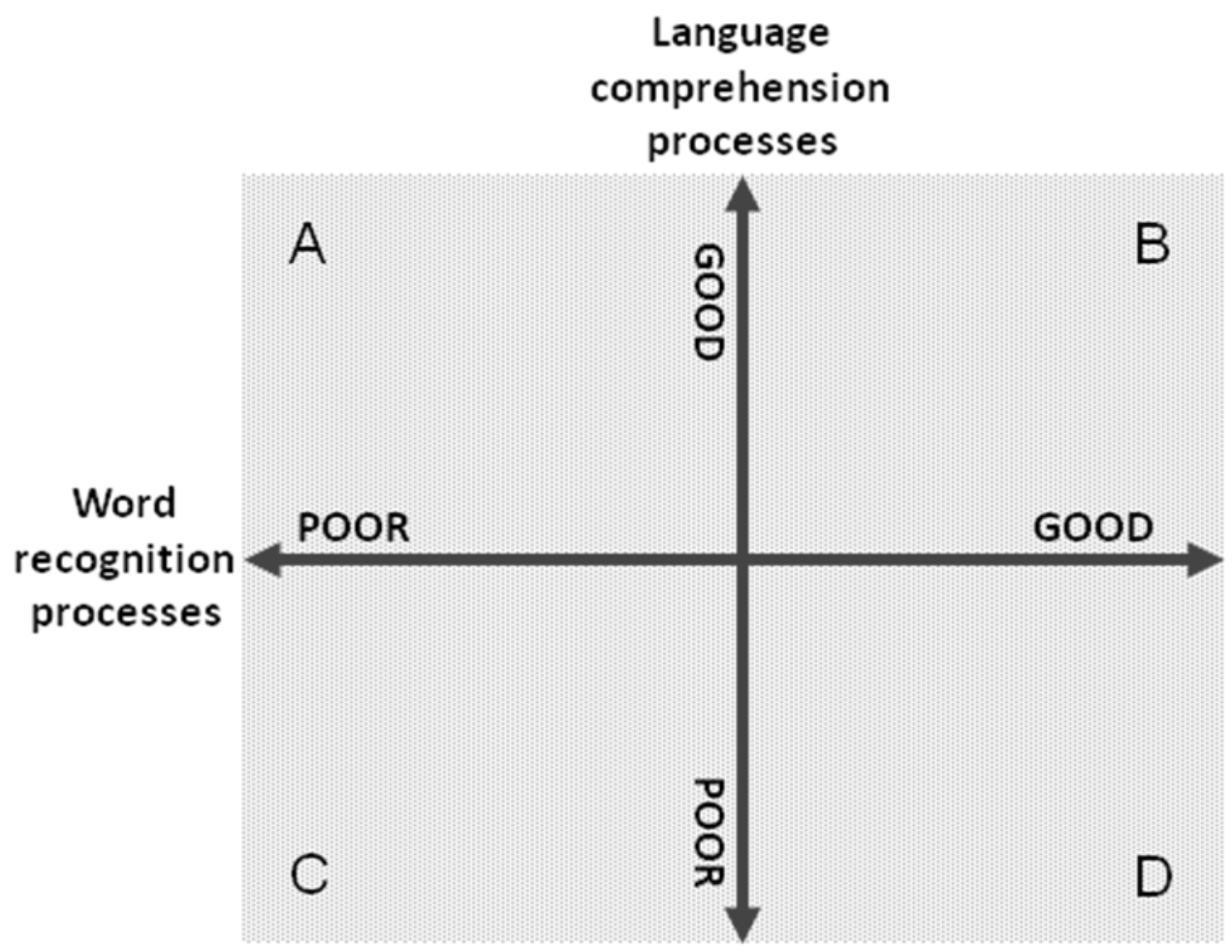

